\title{
BMJ
}

\section{Definition of ambulatory blood pressure targets for diagnosis and treatment of hypertension in relation to clinic blood pressure: prospective cohort study}

Geoffrey A Head, NHMRC principal research fellow and professor of pharmacology, ${ }_{1}^{1}$ Anastasia S Mihailidou, senior hospital scientist and clinical senior lecturer, ${ }^{2}$ Karen A Duggan, associate professor, ${ }^{3}$ Lawrence J Beilin, Winthrop professor of medicine, ${ }^{4}$ Narelle Berry, postdoctoral research fellow, ${ }^{5}$ Mark A Brown, professor of renal medicine, ${ }^{6}$ Alex J Bune, associate professor, ${ }^{7}$ Diane Cowley, clinical nurse consultant, ${ }^{8}$ John P Chalmers, senior director, the George Institute and emeritus professor of medicine, ${ }^{9}$ Peter $\mathrm{R} C \mathrm{C}$ Howe, research professor, ${ }^{5}$ Jonathan Hodgson, professor, ${ }^{4}$ John Ludbrook, professorial fellow, ${ }^{10}$ Arduino A Mangoni, associate professor of clinical pharmacology, ${ }^{11}$ Barry P McGrath, professor of vascular medicine, ${ }^{12}$ Mark R Nelson, professorial fellow, ${ }^{13}$ James E Sharman, senior research fellow, ${ }^{13,14}$ Michael Stowasser, codirector, ${ }^{8}$ for the Ambulatory Blood Pressure Working Group of the High Blood Pressure Research Council of Australia

${ }^{1}$ Baker IDI Heart and Diabetes Institute, Melbourne, Victoria 8008, Australia

${ }^{2}$ Royal North Shore Hospital and University of Sydney, Sydney, Australia

${ }^{3}$ Sydney South West Area Health Service, Sydney

${ }^{4}$ School of Medicine and Pharmacology, University of Western Australia, Royal Perth Hospital, Perth, Australia

${ }^{5}$ Nutritional Physiology Research Centre, University of South Australia, Adelaide, Australia

${ }^{6}$ University of New South Wales, St George Hospital, Sydney

${ }^{7}$ University of Sydney, Royal

Prince Alfred Hospital,

Camperdown, Australia

${ }^{8}$ Hypertension Unit, Princess Alexandra Hospital, University of Queensland School of Medicine, Brisbane, Australia

${ }^{9}$ George Institute, University of Sydney, Sydney

${ }^{10}$ University of Melbourne, Parkville, Australia

${ }^{11}$ Department of Clinical Pharmacology, Flinders University, Adelaide

${ }^{12}$ Monash University, Centre for Vascular Health, Southern Health, Dandenong, Australia

${ }^{13}$ Menzies Research Institute, Hobart, Australia

${ }^{14}$ Endocrine Hypertension Research Centre, School of Medicine, University of Queensland, Brisbane, Australia Correspondence to: G A Head geoff.head@baker.edu.au

Cite this as: BMJ 2010;340:c1104

\section{ABSTRACT}

Background Twenty-four hour ambulatory blood pressure thresholds have been defined for the diagnosis of mild hypertension but not for its treatment or for other blood pressure thresholds used in the diagnosis of moderate to severe hypertension. We aimed to derive age and sex related ambulatory blood pressure equivalents to clinic blood pressure thresholds for diagnosis and treatment of hypertension.

Methods We collated 24 hour ambulatory blood pressure data, recorded with validated devices, from 11 centres across six Australian states $(n=8575)$. We used least product regression to assess the relation between these measurements and clinic blood pressure measured by trained staff and in a smaller cohort by doctors ( $n=1693)$. Results Mean age of participants was 56 years (SD 15) with mean body mass index 28.9 (5.5) and mean clinic systolic/diastolic blood pressure 142/82 $\mathrm{mm} \mathrm{Hg}(19 / 12)$; 4626 (54\%) were women. Average clinic measurements by trained staff were $6 / 3 \mathrm{~mm} \mathrm{Hg}$ higher than daytime ambulatory blood pressure and $10 / 5 \mathrm{~mm} \mathrm{Hg}$ higher than 24 hour blood pressure, but 9/7 mm Hg lower than clinic values measured by doctors. Daytime ambulatory equivalents derived from trained staff clinic measurements were $4 / 3 \mathrm{~mm} \mathrm{Hg}$ less than the $140 / 90 \mathrm{~mm}$ $\mathrm{Hg}$ clinic threshold (lower limit of grade 1 hypertension), $2 / 2 \mathrm{~mm} \mathrm{Hg}$ less than the $130 / 80 \mathrm{~mm} \mathrm{Hg}$ threshold (target upper limit for patients with associated conditions), and $1 / 1 \mathrm{~mm} \mathrm{Hg}$ less than the $125 / 75 \mathrm{~mm} \mathrm{Hg}$ threshold. Equivalents were $1 / 2 \mathrm{~mm} \mathrm{Hg}$ lower for women and $3 /$ $1 \mathrm{~mm} \mathrm{Hg}$ lower in older people compared with the combined group.

Conclusions Our study provides daytime ambulatory blood pressure thresholds that are slightly lower than equivalent clinic values. Clinic blood pressure measurements taken by doctors were considerably higher than those taken by trained staff and therefore gave inappropriate estimates of ambulatory thresholds. These results provide a framework for the diagnosis and management of hypertension using ambulatory blood pressure values.

\section{INTRODUCTION}

Hypertension is a major risk factor for cardiovascular morbidity and mortality. Blood pressure measurements taken in the clinic or office provide limited information about the true blood pressure load, and measurements taken elsewhere are often needed to best guide the diagnosis and treatment of hypertension. Ambulatory blood pressure monitoring is useful in the clinical evaluation of patients with hypertension, especially since it can predict long term end organ damage such as left ventricular hypertrophy. ${ }^{1-3}$ Furthermore, ambulatory measurement is the only commonly used practical method to determine the absence of nocturnal blood pressure dipping, ${ }^{4}$ which is associated with a raised incidence of stroke, ${ }^{5}$ target organ damage, ${ }^{6}$ and other cardiovascular events. ${ }^{7}$ Consensus guidelines for the treatment of hypertension have become increasingly sophisticated and advocate specific goals for individuals at high risk of cardiovascular adverse events, such as those with diabetes, coronary artery disease, or chronic kidney disease. ${ }^{8}$ Most guidelines are based on clinic or office evaluations of blood pressure and similar guidelines are needed for ambulatory blood pressure measurements. ${ }^{9}$

Guidelines for ambulatory blood pressure differ in the thresholds defined as "normal" for triggering management decisions. Recently suggested upper limits for systolic/diastolic blood pressure are 135/85 for daytime, 120/75 for night time, and 130/80 for 24 hour measurements. ${ }^{1011}$ These values have been derived 
doi:10.1136/bmj.c1104 from several sources including population studies, large multicentre studies with participants considered normotensive, ${ }^{12}$ and meta-analyses that correlate ambulatory blood pressure with cardiovascular outcomes. ${ }^{1314}$ These approaches do not necessarily relate to measurements in the clinic on which the guidelines for treatment are based and which are often taken by non-physician health professionals.

An alternative approach has been to determine the relation between office and ambulatory blood pressure measurements by linear regression and use the derived equation to predict the equivalent for the clinic blood pressure of $140 / 90 \mathrm{~mm} \mathrm{Hg}$, which represents mild hypertension. The PAMELA study was a landmark study in this regard, showing a high degree of correlation $(\mathrm{r}=0.66)$ between physician measured clinic blood pressure and ambulatory blood pressure measurements from 1438 participants aged 25 to 65 years from Monza, Italy. ${ }^{15}$ They predicted that a clinic blood pressure measure of $140 / 90 \mathrm{~mm} \mathrm{Hg}$ was equivalent to a 24 hour ambulatory blood pressure value of $125 / 80 \mathrm{mmHg}$ and a daytime value of $130 / 85 \mathrm{~mm} \mathrm{Hg}$ in men and slightly less in women.

A strength of the PAMELA study was that it was conducted in a random sample of people from the general population. It provided a method by which ambulatory blood pressure could be related to outcome data that had been defined in terms of clinic blood pressure. Subsequent studies from Scandinavian ${ }^{16}$ and South American ${ }^{18}$ populations used similar approaches. However, no published studies have defined the ambulatory blood pressure levels that are equivalent to the various treatment targets used for hypertensive people with comorbidities, or to the blood pressure levels used to classify severity of hypertension.

In this multicentre study, we used clinic and ambulatory blood pressure measurements to obtain reference ambulatory blood pressure thresholds for the diagnosis and management of hypertension that accounted for age and sex. We also compared clinic measurements taken by non-medically qualified health professionals with those taken by doctors, to assess whether a "white coat" effect might have influenced the findings of previous studies that were based on doctor's measurements alone.

\section{METHODS}

We recruited 8529 participants from 11 hypertension clinics, representing all six Australian states, to compare measurements of clinic blood pressure and 24 hour ambulatory blood pressure (see supplementary table S3 for detailed characteristics of participants by state). Most participants had been referred by doctors to the ambulatory blood pressure service for evaluation of their 24 hour blood pressure. The people recruited were therefore typical of those referred for ambulatory assessment, which generally included individuals with suspected white coat hypertension, resistant or difficult to treat hypertension, or hypertension associated with renal disease, and individuals whose referring physician was unsure whether antihypertensive medication was required. Some centres recruited by advertising from the general population and contributed a substantial proportion of healthy participants. Age, sex, ethnicity, body mass index, and hypertensive treatment status were also recorded if available.

\section{Cardiovascular measurements}

Ambulatory blood pressure was recorded for at least a 24 hour period during a typical day using validated devices (SpaceLabs $90207^{19}$ or $90217,{ }^{19}$ SpaceLabs Medical, Redmond, WA, United States; A\&D model TM2430, ${ }^{19}$ A\&D Medical, Kensington, VIC, or Seven Hills, NSW, Australia; Accutracker ${ }^{20}$ or Oscar $2,{ }^{21}$ Suntech Medical Instruments, Raleigh, NC, United States). Values were also assessed according to clock times with 07:00 to 23:00 being considered as day and 23:00 to 07:00 as night in two centres or according to patient reported sleep periods in nine centres (see Web Extra supplement for further details).

In the majority of instances clinic blood pressure was measured by non-medically qualified professional staff (research nurses and research staff) trained in the measurement of blood pressure. Datasets from four centres included the referring doctor's clinic blood pressure measurement; only those taken within two weeks of the ambulatory blood pressure measurement $(n=1593)$ were used for analysis. Clinic blood pressure was measured after a 10 minute rest using an appropriately sized cuff and a mercury sphygmomanometer in all but three minor contributing centres (total 7.3\% of the data), where a digital device (such as Dinamap or Omron) was used. For sphygmomanometer readings systolic and diastolic pressures were identified as the first and fifth Korotkoff sounds, respectively, which were elicited by deflating the cuff at a rate of $2 \mathrm{~mm}$ $\mathrm{Hg}$ per second. Depending on clinic protocols, blood pressure was measured after at least 10 minutes in the seated position and also in the semi-recumbent position ( $45^{\circ}$ on the examination couch). Sitting and reclining clinic measurements were available for 1260 participants. The average number of clinic measurements across the 11 centres was 2.8 readings with an average of 2.4 readings used per person if the initial measurement was excluded.

We determined ambulatory blood pressure equivalents for the lower limits of grade 3 (severe) hypertension $(180 / 110 \mathrm{~mm} \mathrm{Hg})$, grade 2 (moderate) hypertension $(160 / 100 \mathrm{~mm} \mathrm{Hg})$, grade 1 (mild) hypertension (140/90 mm $\mathrm{Hg}$ ); for target upper limits for hypertension with associated conditions $(130 / 80 \mathrm{~mm}$ $\mathrm{Hg}$ ) and hypertension with substantial proteinuria (125/75 mm Hg); and for the upper limit of optimal normal $(120 / 80 \mathrm{~mm} \mathrm{Hg})$. These levels were chosen to encompass the recommendations by the National Heart Foundation of Australia, ${ }^{8}$ the American Heart Association, ${ }^{22}$ the European Society of Hypertension, ${ }^{23}$ the British Hypertension Society, ${ }^{24}$ 
and the Canadian Hypertension Education Program. ${ }^{25}$

Comparison between ambulatory equivalents for PAMELA study and Australian data

We compared data from the PAMELA study ${ }^{15}$ with our predicted ambulatory blood pressure equivalents for the lower limits of grade one hypertension. We also undertook a comparison with the PAMELA data after exclusion from our dataset of participants treated with antihypertensive agents, restriction to the age range (25-64) used in PAMELA, and adjustment of the percentage of men to women to match that in PAMELA by removing a small proportion of women (3.3\%) from the dataset at random but evenly across the age deciles. This resulted in a group of 1027 individuals with mean age, age range, and sex ratio identical to those in the PAMELA group.

\section{Statistical analysis}

Data are presented as mean (SD) of the between participant variation. Differences between groups were compared by Student's $t$ test and were considered significant if $\mathrm{P}<0.05$. We used ordinary least product linear regression equations between clinic and ambulatory blood pressure values to generate ambulatory blood pressure equivalents for target clinic values and to determine fixed and proportional bias using

Table 1/Characteristics of patients by method of clinic blood pressure measurement

\begin{tabular}{lccc} 
& $\begin{array}{c}\text { Staff } \\
\text { measured } \\
\text { blood } \\
\text { pressure } \\
(\mathrm{n}=8529)\end{array}$ & $\begin{array}{c}\text { Doctor } \\
\text { measured } \\
\text { blood } \\
\text { pressure } \\
(\mathrm{n}=1593)\end{array}$ & $\begin{array}{c}\text { Pfor differences } \\
\text { between } \\
\text { groups }\end{array}$ \\
\hline Age in years & $56.4(15.4)$ & $53.8(15.9)$ & $<0.001$ \\
\hline Age range & $18-98$ & $18-94$ & - \\
\hline Body mass index & $28.9(5.5)$ & $28.9(5.5)$ & 0.719 \\
\hline Female sex (\%) & $4626(54 \%)$ & $886(56 \%)$ & - \\
\hline $\begin{array}{l}\text { Treated } \\
\text { hypertensives (\%) }\end{array}$ & $5866(69 \%)$ & $1138(71 \%)$ & - \\
\hline White (\%) & $7026(82 \%)$ & $1313(82 \%)$ & - \\
\hline Asian (\%) & $1290(15 \%)$ & $264(17 \%)$ & - \\
\hline
\end{tabular}

Office blood pressure $(\mathrm{mm} \mathrm{Hg})$

\begin{tabular}{lccc}
\hline $\begin{array}{l}\text { Seated } \\
\text { measurements }\end{array}$ & 5327 & 1490 & - \\
\hline Systolic seated & $141.6(19.0)$ & $150.2(23.7)$ & $<0.001$ \\
\hline Diastolic seated & $81.7(12.1)$ & $88.8(12.9)$ & $<0.001$ \\
\hline $\begin{array}{l}\text { Reclining } \\
\text { measurements }\end{array}$ & 3399 & 1165 & - \\
\hline Systolic reclining & $142.3(21.0)$ & $151.8(22.8)$ & $<0.001$ \\
\hline Diastolic reclining & $83.8(12.1)$ & $88.7(11.9)$ & $<0.001$ \\
\hline Ambulatory blood pressure (mm Hg) & & \\
\hline 24 hour systolic & $132.0(14.6)$ & $132.1(14.8)$ & 0.867 \\
\hline 24 hour diastolic & $76.6(10.2)$ & $77.3(10.4)$ & 0.013 \\
\hline Day systolic & $135.5(14.8)$ & $135.5(15.0)$ & 0.938 \\
\hline Day diastolic & $79.2(10.6)$ & $80.0(10.9)$ & 0.007 \\
\hline Night systolic & $120.5(17.0)$ & $120.8(17.4)$ & 0.509 \\
\hline Night diastolic & $67.8(10.3)$ & $68.3(10.9)$ & 0.075 \\
\hline
\end{tabular}

Values presented as total, percentage of total, or mean (SD).
SYSTAT 12 (Systat Software, Chicago, United States). Plots of residuals were used to determine homogeneity of variance. Further details of the method of analysis are included in the supplementary data.

\section{RESULTS}

\section{Participants' characteristics}

We recruited 8529 individuals from eleven hypertension referral centres; 4626 (54\%) were women. The average age was 56 years (SD 16, range 14-98, median 57 ) and average body mass index was $28.9 \mathrm{~kg} / \mathrm{m}^{2}$ (SD 5.5). A large proportion were receiving medications for hypertension $(\mathrm{n}=5866,69 \%)$ and most were white ( $\mathrm{n}=7026,82 \%)$. The mean seated clinic systolic/diastolic blood pressure measured by trained staff was 142/ $82 \mathrm{~mm} \mathrm{Hg}$ (SD 19/12) and mean reclining systolic/ diastolic blood pressure was 142/84 mm Hg (21/12) (table 1). A smaller sample $(\mathrm{n}=1593)$ with measurements taken by doctors had similar characteristics to patients who had measurements taken by trained staff but their clinic measurements showed higher blood pressure $(\mathrm{P}<0.001)$, seated systolic/diastolic blood pressure (mean 150/89 mm Hg, SD 24/13), and reclining values (152/89 mm Hg, 23/12) (table 1). No differences in day, night, or 24 hour ambulatory systolic blood pressure were noted between the two groups but ambulatory diastolic blood pressure was slightly lower for the trained staff measurement group than the doctor measurement group (significantly so for 24 hour and daytime levels, table 1).

Ambulatory equivalents for seated clinic blood pressure measured by non-physician professional staff

A least product regression analysis showed a high degree of association between seated clinic blood pressure measured by trained staff and 24 hour, daytime, and night time ambulatory blood pressure. The correlation was highest for daytime ambulatory blood pressure values $(\mathrm{r}=0.64$ for systolic and $\mathrm{r}=0.73$ for diastolic blood pressure) and 24 hour ambulatory blood pressure ( $\mathrm{r}=0.64$ systolic and $\mathrm{r}=0.73$ diastolic; fig 1 , supplementary table S1). Night time ambulatory blood pressure values were less well correlated $(\mathrm{r}=0.49$ and $\mathrm{r}=0.55)$. Slopes for least product regression in all cases were slightly less than 1 (range $0.77-0.92$ ) indicating proportional bias $(95 \%$ confidence intervals for slope did not include 1) and fixed bias (95\% confidence intervals for intercept for daytime and 24 hour regressions did not include zero) (supplementary table S1). In each case least product regression slopes were greater than least squares regression estimates (range 0.45-0.65) and the least product regression lines followed closely the major axis of the ellipse of data points, unlike the least squares regression (figure). Residual plots showed uniform variance across predicted y (data not shown).

The daytime systolic/diastolic ambulatory blood pressure equivalent to the lower limit of grade 1 or mild hypertension was estimated to be $4 / 3 \mathrm{~mm} \mathrm{Hg}$ lower than seated clinic values (table 2 ); the estimate for grade 2 hypertension was $8 / 4 \mathrm{~mm} \mathrm{Hg}$ lower and for 

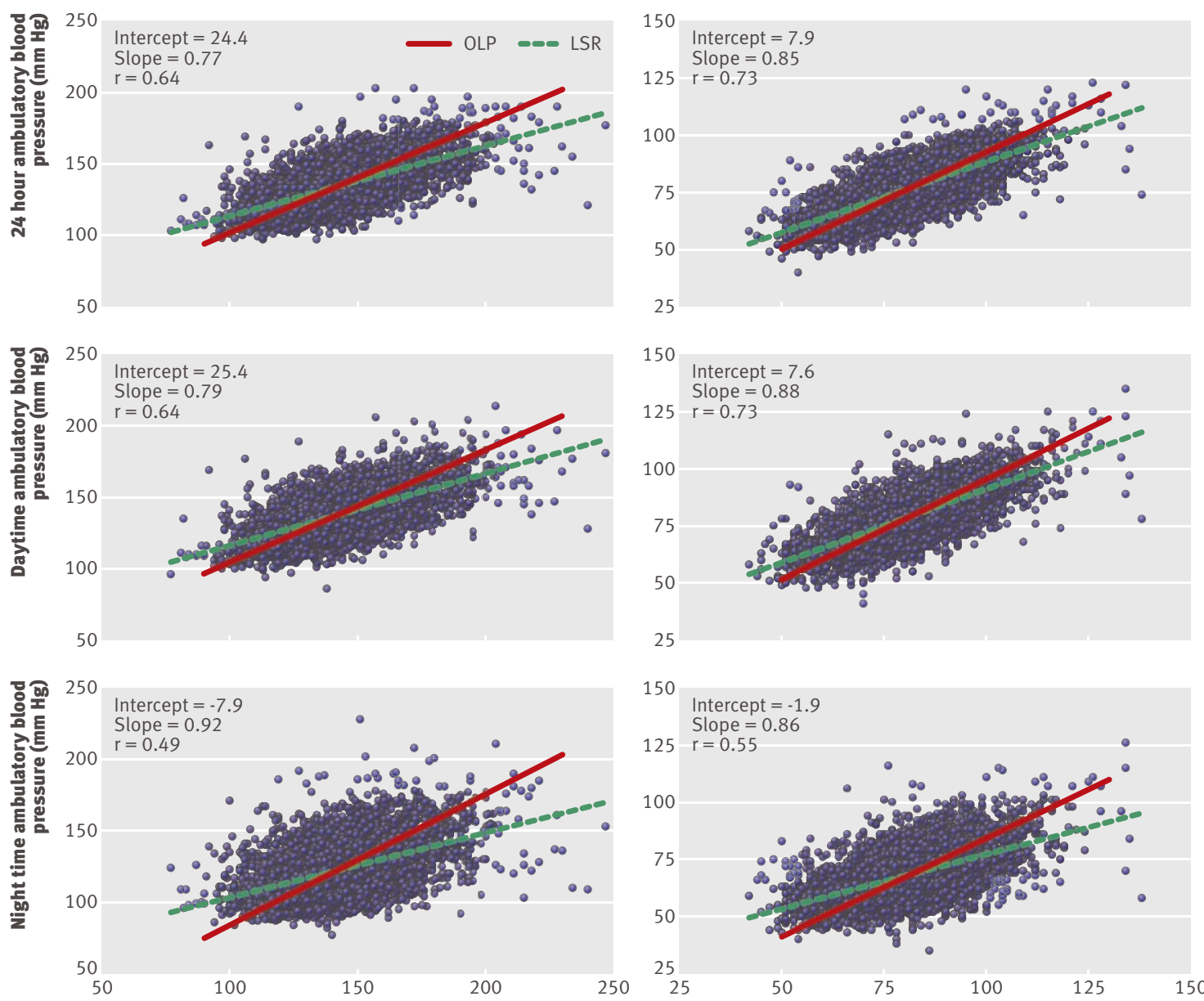

Clinic sitting systolic blood pressure (mm Hg)

Clinic sitting diastolic blood pressure $(\mathbf{m m ~ H g})$

Pearson correlation between seated clinic systolic and diastolic blood pressure and 24 hour, daytime, and night time ambulatory blood pressure measurements in 5327 participants for whom measurements were available. Dashed lines indicate least squares linear regression (LSR), straight lines indicate ordinary least product (OLP) linear regression. Intercept, slope, and correlation coefficient $(r)$ is shown for each OLP regression

grade 3 hypertension was $12 / 6 \mathrm{~mm} \mathrm{Hg}$ lower. The equivalent target for ambulatory blood pressure in patients with an associated condition or risk factor was $2 / 2 \mathrm{~mm} \mathrm{Hg}$ lower than the seated clinic values and the equivalent for ambulatory blood pressure in healthy people was $1 / 1 \mathrm{~mm} \mathrm{Hg}$ lower. Daytime diastolic ambulatory blood pressure equivalents were not affected by age but systolic equivalents were $2-4 \mathrm{~mm}$ $\mathrm{Hg}$ lower in people aged 65 years or older than in those aged 25-44 years and 1-2 $\mathrm{mm} \mathrm{Hg}$ lower than those aged 45-64. Systolic and diastolic ambulatory blood pressure equivalents were $3 / 2 \mathrm{~mm} \mathrm{Hg}$ lower for women than for age matched men (table 3 ). When reclining estimates were used for clinic blood pressure,

Table 2| Systolic/diastolic ambulatory blood pressure (ABP) values predicted from seated clinic blood pressure levels; values in $\mathrm{mm} \mathrm{Hg}$

\begin{tabular}{|c|c|c|c|c|c|c|c|}
\hline & \multirow{2}{*}{$\begin{array}{c}\text { Clinic blood } \\
\text { pressure } \\
\text { threshold }\end{array}$} & \multicolumn{3}{|c|}{$\begin{array}{l}\text { ABP predicted from staff measured } \\
\text { seated clinic blood pressure }(n=5327)\end{array}$} & \multicolumn{3}{|c|}{$\begin{array}{l}\text { ABP predicted from doctor measured } \\
\text { seated clinic blood pressure }(n=1490)\end{array}$} \\
\hline & & 24 hour & Night & Day & 24 hour & Night & Day \\
\hline Grade 3 (severe) hypertension & $>180 / 110$ & $163 / 101$ & $157 / 93$ & $168 / 105$ & $151 / 95$ & $143 / 86$ & $155 / 98$ \\
\hline $\begin{array}{l}\text { Grade } 2 \text { (moderate) } \\
\text { hypertension }\end{array}$ & $>160 / 100$ & $148 / 93$ & $139 / 84$ & $152 / 96$ & $138 / 86$ & $128 / 78$ & $142 / 90$ \\
\hline Grade 1 (mild) hypertension & $>140 / 90$ & $133 / 84$ & $121 / 76$ & $136 / 87$ & $126 / 78$ & $113 / 69$ & $129 / 81$ \\
\hline $\begin{array}{l}\text { Target blood pressure plus one } \\
\text { condition }\end{array}$ & $<130 / 80$ & $125 / 76$ & $112 / 67$ & $128 / 78$ & $119 / 70$ & $106 / 61$ & $123 / 73$ \\
\hline $\begin{array}{l}\text { Target blood pressure with } \\
\text { proteinuria }\end{array}$ & $<125 / 75$ & $121 / 71$ & $107 / 63$ & $124 / 74$ & $116 / 66$ & $102 / 57$ & $120 / 69$ \\
\hline Normal blood pressure & $<120 / 80$ & $117 / 76$ & $102 / 67$ & $120 / 78$ & $113 / 70$ & $99 / 61$ & $117 / 70$ \\
\hline
\end{tabular}


ambulatory equivalents were another $3-4 \mathrm{~mm} \mathrm{Hg}$ lower (daytime $-9 /-6$ for $140 / 90 \mathrm{~mm} \mathrm{Hg}$ and $-5 /-4$ for 130/80 mm Hg) (see supplementary table S2).

\section{Ambulatory equivalents for seated clinic blood pressure measured by doctor}

In a separate analysis, we compared 1593 doctor measured clinic blood pressure values with ambulatory blood pressure by least product regression to determine whether ambulatory thresholds differed from those calculated using values measured by trained staff. The regression degree of correlation was somewhat lower in this group than in the larger group, with $r$ values ranging from 0.41 to 0.54 (supplementary figure S1). While slopes and intercepts differed from 1 and zero respectively, indicating similar fixed and proportional bias to the main study, the least product regression lines followed the major axis of the data ellipsoid. The daytime systolic/diastolic ambulatory blood pressure indicating the minimum for grade 1 hypertension was estimated to be $11 / 9 \mathrm{~mm} \mathrm{Hg}$ lower than the equivalent clinic value (table 2); for target blood pressure in patients with one condition the equivalent was $7 / 7 \mathrm{~mm} \mathrm{Hg}$ lower, and for the upper limit of normal blood pressure the equivalent was $3 / 10 \mathrm{~mm} \mathrm{Hg}$ lower. In men and women the ambulatory equivalents for daytime diastolic pressure were not affected by age, but those for systolic pressure were lower in older people than in younger ones (table 3 ).

Comparison between ambulatory equivalents for PAMELA study and Australian data

Although the study populations differed in that clinic and ambulatory blood pressure were lower for the PAMELA study than for the Australian data, even after adjustment for age, sex, and treatment status, the daytime ambulatory blood pressure equivalents for doctor measured clinic blood pressure of 140/90 mm $\mathrm{Hg}$ in PAMELA were almost identical to those in the present study (within $1 \mathrm{~mm} \mathrm{Hg}$; table 4). Limiting the Australian participants to match those of the PAMELA study by age, sex, and treatment status did not alter this value. Furthermore, the daytime ambulatory blood pressure equivalents for trained staff measured clinic blood pressure of 140/90 were $8 / 5 \mathrm{~mm} \mathrm{Hg}$ higher than those of the PAMELA study and again were not affected by limiting the participants to match the criteria of the PAMELA study $(10 / 5 \mathrm{~mm} \mathrm{Hg})$ (table 4).

\section{Comparison between clinic sitting and reclining blood pressure}

To determine whether reclining clinic measurements could also be substituted for seated equivalents, we examined the relation between these two measurements in a subgroup of 1267 participants. There was a very high correlation between clinic blood pressure measured sitting and reclining $(\mathrm{r}=0.85$ for systolic blood pressure and 0.81 for diastolic blood pressure). Diastolic blood pressures were effectively the same in either position since the slope and intercept 95\% CIs overlapped with 1 and 0, respectively. Systolic blood pressures were slightly higher in the reclining than in the sitting position, but only at higher systolic blood pressure values $(3 \mathrm{~mm} \mathrm{Hg}$ higher at $120 \mathrm{~mm} \mathrm{Hg}$ and $5 \mathrm{~mm} \mathrm{Hg}$ higher at $160 \mathrm{~mm} \mathrm{Hg}$, paired t test, $\mathrm{P}<0.0001$, $\mathrm{t}=14$ ).

\section{DISCUSSION}

We used least product regression to provide ambulatory blood pressure equivalents for the definition of hypertension and its severity and for common treatment targets based on seated clinic measurements. When measurements were taken by trained staff, the daytime ambulatory blood pressure equivalents for the lower limit of grade 1 hypertension (140/90 mm Hg) were $4 / 3 \mathrm{~mm} \mathrm{Hg}$ lower than the clinic values. For the target clinic value in patients with one associated clinical condition $(130 / 80 \mathrm{~mm} \mathrm{Hg})$ the daytime ambulatory blood pressure equivalent was $2 / 2 \mathrm{~mm} \mathrm{Hg}$ lower, and for patients with significant proteinuria who require a target clinic blood pressure of 125/ $75 \mathrm{~mm} \mathrm{Hg}$, the daytime ambulatory equivalent was 1/1 mm Hg lower. Thus our analysis shows that the closer the patient's blood pressure is to normal levels, the closer is the agreement between daytime ambulatory and clinic blood pressure. On the other hand, the higher the blood pressure, the greater the difference between ambulatory and clinic blood pressure.

Table 3|Daytime systolic/diastolic ambulatory blood pressures by age and sex predicted from seated clinic blood pressure levels measured by staff; values in $\mathrm{mm} \mathrm{Hg}$

\begin{tabular}{|c|c|c|c|c|c|c|c|c|c|c|}
\hline & \multirow[b]{2}{*}{$\begin{array}{l}\text { Clinic seated blood } \\
\text { pressure }\end{array}$} & \multicolumn{3}{|c|}{ Combined $(n=5327)$} & \multicolumn{3}{|c|}{ Men } & \multicolumn{3}{|c|}{ Women } \\
\hline & & 24-hour & Night & Day & $\begin{array}{c}25-44 \\
(n=468)\end{array}$ & $\begin{array}{c}45-64 \\
(n=1057)\end{array}$ & $\begin{array}{c}\geq 65 \\
(n=800)\end{array}$ & $\begin{array}{c}25-44 \\
(n=616)\end{array}$ & $\begin{array}{c}45-64 \\
(n=1112)\end{array}$ & $\begin{array}{c}\geq 65 \\
(n=1094)\end{array}$ \\
\hline Grade 3 hypertension & $>180 / 110$ & $163 / 101$ & $157 / 93$ & $168 / 105$ & $176 / 104$ & $170 / 105$ & $167 / 104$ & $171 / 105$ & $167 / 103$ & $164 / 102$ \\
\hline Grade 2 hypertension & $>160 / 100$ & $148 / 93$ & $139 / 84$ & $152 / 96$ & $158 / 96$ & $154 / 96$ & $151 / 96$ & $154 / 96$ & $151 / 95$ & $149 / 93$ \\
\hline Grade 1 hypertension & $>140 / 90$ & $133 / 84$ & $121 / 76$ & $136 / 87$ & $140 / 87$ & $138 / 88$ & $136 / 87$ & $137 / 87$ & $135 / 86$ & $133 / 85$ \\
\hline $\begin{array}{l}\text { Target blood pressure } \\
\text { plus one condition }\end{array}$ & $<130 / 80$ & $125 / 76$ & $112 / 67$ & $128 / 78$ & $131 / 79$ & $130 / 79$ & $128 / 79$ & $129 / 78$ & $126 / 77$ & $125 / 77$ \\
\hline $\begin{array}{l}\text { Target blood pressure } \\
\text { with proteinuria }\end{array}$ & $<125 / 75$ & $121 / 71$ & $107 / 63$ & $124 / 74$ & $127 / 75$ & $126 / 75$ & $125 / 75$ & $124 / 73$ & $122 / 73$ & $121 / 72$ \\
\hline $\begin{array}{l}\text { Normal blood } \\
\text { pressure }\end{array}$ & $<120 / 80$ & $117 / 76$ & $102 / 67$ & $120 / 78$ & $122 / 79$ & $122 / 79$ & $121 / 79$ & $120 / 78$ & $118 / 77$ & $118 / 77$ \\
\hline
\end{tabular}


Table 4 |Predicted systolic/diastolic ambulatory blood pressure from PAMELA study and the present study measured by physician or staff, with and without age and treatment restrictions. Blood pressure values in $\mathrm{mm} \mathrm{Hg}$.

\begin{tabular}{|c|c|c|c|c|c|}
\hline & \multirow[b]{2}{*}{ PAMELA $(n=1438)$} & \multicolumn{2}{|c|}{ Present study: doctor measured } & \multicolumn{2}{|c|}{ Present study: staff measured } \\
\hline & & $\begin{array}{l}\text { Combined seated } \\
\qquad(n=1490)\end{array}$ & $\begin{array}{l}\text { Combined seated (age, sex, } \\
\text { treatment adjusted) }(n=112)\end{array}$ & $\begin{array}{l}\text { Combined seated } \\
\quad(n=5327)\end{array}$ & $\begin{array}{l}\text { Combined seated (age, sex, } \\
\text { treatment adjusted) } \\
(n=1027)\end{array}$ \\
\hline Female sex & $50.8 \%$ & $833(55.9 \%)$ & $58(50.9 \%)$ & $2888(54.2 \%)$ & $522(50.9 \%)$ \\
\hline Treated individuals excluded & Yes & No & Yes & No & Yes \\
\hline Mean age in years (SD) & $46.4(11.9)$ & $53.6(15.8)$ & $42.1(10.7)$ & $57.2(15.9)$ & $46.3(10.2)$ \\
\hline Age range & $25-64$ & $15-94$ & $25-64$ & $18-98$ & $25-64$ \\
\hline Clinic blood pressure & $128 / 82$ & $150 / 89$ & $146 / 91$ & $142 / 82$ & $137 / 87$ \\
\hline \multicolumn{6}{|c|}{ Absolute ambulatory blood pressure } \\
\hline 24 hour & $118 / 74$ & $132 / 77$ & $127 / 80$ & $134 / 77$ & $132 / 82$ \\
\hline Daytime & $123 / 79$ & $136 / 80$ & $132 / 83$ & $137 / 80$ & $136 / 85$ \\
\hline Night time & $108 / 64$ & $121 / 68$ & $113 / 68$ & $122 / 68$ & $117 / 71$ \\
\hline \multicolumn{6}{|c|}{ Predicted ambulatory blood pressure for grade 1 hypertension (clinic blood pressure 140/90) } \\
\hline 24 hour & $123 / 77$ & $126 / 78$ & $123 / 78$ & $133 / 84$ & $134 / 85$ \\
\hline Daytime & $128 / 82$ & $129 / 81$ & $128 / 82$ & $136 / 87$ & $138 / 88$ \\
\hline $\begin{array}{l}\text { Daytime difference between } \\
\text { PAMELA and present study }\end{array}$ & & $1 /-1$ & $-1 /-1$ & $8 / 5$ & $10 / 5$ \\
\hline Night time & $112 / 67$ & $113 / 69$ & $109 / 66$ & $121 / 76$ & $119 / 74$ \\
\hline
\end{tabular}

\section{Comparison with other studies}

Previous studies have mainly concentrated on defining the upper limit of normal for ambulatory blood pressure and have not extended the analysis to predictions for grade 2 (moderate) or grade 3 (severe) hypertension or to lower blood pressure targets adjusted for comorbidities such as diabetes and renal disease. Consensus papers from an ad hoc committee of the American Society of Hypertension ${ }^{26}$ and from the National Heart Foundation of Australia ${ }^{11}$ have concluded that the daytime ambulatory blood pressure equivalent for the lower limit of grade 1 hypertension (140/90) is $135 / 85 \mathrm{~mm} \mathrm{Hg}$, which is similar to but slightly less than the equivalent values of $136 / 87 \mathrm{~mm} \mathrm{Hg}$ determined in the present study.

The consensus papers have been mainly based on large, multicentre randomised population studies involving measurements from people considered normotensive ${ }^{12}$ and from the PAMELA study of normotensive people from Monza, Italy. ${ }^{15}$ The latter study predicted somewhat lower ambulatory blood pressure equivalents than our study (for clinic 140/90 mm Hg, equivalents of 128/82 mm Hg for daytime and 125/ $80 \mathrm{~mm} \mathrm{Hg}$ for 24 hour). Nevertheless, when we limited our data set to the same age range, excluded treated participants, and adjusted the male to female ratio to be identical to that of the PAMELA cohort, these changes made little difference to the predicted values.

The main difference seems to arise from the fact that in the PAMELA study clinic blood pressure was measured by doctors, since the differences between studies was almost eliminated when we used only the blood pressure values measured by doctors. Therefore the most likely reason for our study showing greater equivalence between clinic and daytime ambulatory blood pressure is that we have reduced the "white coat" effect by using clinic blood pressures measured by trained staff. Our finding that blood pressure recorded by doctors was higher by $9 / 7 \mathrm{~mm} \mathrm{Hg}$ than that recorded by other health professionals is in accord with previous studies that compared nurse and doctor measured blood pressure. ${ }^{27}$ A large study by La BatideAlanore and colleagues showed that nurses recorded $6 / 8 \mathrm{~mm} \mathrm{Hg}$ lower blood pressure than doctors. ${ }^{28}$ This finding led to the suggestion that routine management of the hypertensive patient should not rely solely on the doctor's assessment of blood pressure. ${ }^{28}$ Their finding that the nurse recorded blood pressure was closer to the patient's daytime average ambulatory blood pressure than the pressure recorded by the doctor also closely concurs with the current study.

One of the major differences between the population samples from our present study and previous reports is that we included a higher proportion of patients given antihypertensive medication who were referred for assessment of the effectiveness of treatment. ${ }^{1316}{ }^{17}$ Little difference was observed in the predicted values when treated participants were excluded, suggesting that treatment does not significantly affect the relation between clinic and ambulatory blood pressure measurements per se. These adjustments also included a slight change in the male to female ratio and age range but this does not indicate that age and sex were not important in the calculations of ambulatory blood pressure equivalents. Estimates were 2-3 mm Hg lower for women than men for systolic and diastolic blood pressure and lower in older participants of both sexes, but only for systolic blood pressure. Thus more accurate ambulatory blood pressure treatment targets may be attained by taking age and sex into consideration.

\section{Strengths and limitations of study}

A strength of the present study is that analyses were based on patients for whom treatment equivalents are 


\section{WHAT IS ALREADY KNOWN ON THIS TOPIC}

Ambulatory blood pressure predicts cardiovascular outcome better than clinic blood

pressure, with known equivalent thresholds for diagnosis of mild hypertension

Guidelines for management of hypertension in patients with pre-existing cardiovascular disease or risk factors suggest that target values should be different from those in patients without such factors, but ambulatory equivalents have not been defined

Blood pressure measured in the clinic by doctors tends to be higher than that measured by nurses

\section{WHAT THIS STUDY ADDS}

Regression analysis showed that the hypertension thresholds and target values for daytime ambulatory blood pressure were slightly lower than the equivalent clinic values

Ambulatory values were $1 / 2 \mathrm{~mm} \mathrm{Hg}$ lower for women than for men and 3/1 $\mathrm{mm} \mathrm{Hg}$ lower in older people ( $\geq 65$ years) than in younger people

Because doctors' measurements of clinic blood pressure were higher than those of trained staff, they are inappropriate for estimation of ambulatory blood pressure treatment thresholds guidelines can include the thresholds identified in the current study to guide management of hypertension.

This research is part of a joint initiative between the High Blood Pressure Research Council of Australia and the National Heart Foundation of Australia, which aims to support appropriate use and interpretation of ambulatory blood pressure monitoring and effective management of blood pressure in the primary care setting.

Contributors: GAH was involved in study conception and design, study supervision, statistical analysis, preparation of graphs and tables, data interpretation, and drafting, revision, and finalising of the paper. ASM and KAD were involved in study conception and design, study supervision, data interpretation and drafting, revision, and finalising of the paper. NB, MAB, DC, PRCH, JH, AAM, BPM, MRN, and JES and were involved in study supervision, data interpretation, and revision and finalising of the paper. $L J B, A J B, M S$, and JPC and were involved in data interpretation and revision and finalising of the paper. IL was the study statistician and was involved in data analysis, drafting and revision of the paper. GAH is the guarantor. All authors had full access to all the data (including statistical reports and tables) in the study and take responsibility for the integrity of the data and the accuracy of the data analysis. We thank Kanella Chatzivlastou, Melinda Carrington, Carla M. Morley, Kim N Do, Karen Hall, Mark J Penny, Lai H Siew, and Agnes Ross for contributions to collection and analysis of data.

Funding: Financial sponsorship was supplied to the first author, GAH, for the analysis of the data from the High Blood Pressure Research Council of Australia. All authors are members of the council.

Competing interests: All authors have completed the Unified Competing Interest form, which is available on request from the corresponding author. The authors declare that (1) no authors have support from any company for the submitted work; (2) no authors have any relationships with companies that might have an interest in the submitted work in the previous 3 years; (3) their spouses, partners, or children have no financial relationships that may be relevant to the submitted work; and (4) no authors have non-financial interests that may be relevant to the submitted work.

Ethical approval: Ethics committee approval was not required because we used anonymised data.

Data sharing: no additional data available. particularly in cases where there is systematic and proportional bias (making the least squares method inappropriate). ${ }^{29}$ This can be clearly appreciated by inspection of the regression lines and data distribution where the least product method, but not the least squares method, followed the major axis of the ellipsoid.

A possible limitation of our study is that we have used the larger population (with and without comorbidities) in the regression analysis to predict target values for each, respectively. Thus a further future refinement would be to document and adjust for comorbidities and to determine whether this makes a significant difference in the predictive values.

\section{Conclusions and policy implications}

In conclusion, the present study provides a range of daytime ambulatory blood pressure measurements equivalent to recognised diagnostic thresholds and target clinic blood pressure. These values are only slightly below clinic values measured by trained staff and can be used to guide the management of hypertension. It also provides separate ambulatory blood pressure targets for men and women at different ages. The benefits of this study are that we used blood pressure measurements from both treated and untreated individuals, a population that is representative of clinical practice. Current hypertension guidelines propose operational thresholds for normality. We now suggest that the
1 Khattar RS, Senior R, Swales JD, Lahiri A. Value of ambulatory intraarterial blood pressure monitoring in the long-term prediction of left ventricular hypertrophy and carotid atherosclerosis in essential hypertension. J Hum Hypertens 1999;13:111-6.

2 Williams B. The year in hypertension. J Am Coll Cardiol 2006;48:1698-711.

3 Sega R, Facchetti R, Bombelli M, Cesana G, Corrao G, Grassi G, et al. Prognostic value of ambulatory and home blood pressures compared with office blood pressure in the general population: follow-up results from the Pressioni Arteriose Monitorate e Loro Associazioni (PAMELA) study. Circulation 2005;111:1777-83.

4 Staessen JA, Bieniaszewski L, O’Brien E, Gosse P, Hayashi H, Imai Y, et al. Nocturnal blood pressure fall on ambulatory monitoring in a large international database. The "Ad Hoc" Working Group. Hypertension 1997;29:30-9.

5 Phillips RA, Butkevich A, Sheinart KF, Tuhrim S. Dipping is superior to cusums analysis in assessment of the risk of stroke in a case-control study. Am / Hypertens 2001;14:649-52.

6 Verdecchia P, Schillaci G, Borgioni C, Ciucci A, Pede S, Porcellati C. Ambulatory pulse pressure: a potent predictor of total cardiovascular risk in hypertension. Hypertension 1998;32:983-8.

7 Zweiker R, Eber B, Schumacher M, Toplak H, Klein W. "Non-dipping" related to cardiovascular events in essential hypertensive patients. Acta Med Austriaca 1994;21:86-9.

8 National Heart Foundation of Australia. Guide to management of hypertension 2008. Assessing and managing raised blood pressure in adults. 2008. www.heartfoundation.org.au/ SiteCollectionDocuments/ A_Hypert_Guidelines2008_2009Update_FINAL.pdf.

9 White WB. Ambulatory blood-pressure monitoring in clinical practice. N Engl J Med 2003;348:2377-8.

10 O'Brien E, Coats A, Owens P, Petrie J, Padfield PL, Littler WA, et al. Use and interpretation of ambulatory blood pressure monitoring: recommendations of the British Hypertension Society. $B M$ 2000;320:1128-34

11 McGrath BP. Ambulatory blood pressure monitoring. Med J Aust 2002;176:588-92.

12 Staessen JA, O'Brien ET, Amery AK, Atkins N, Baumgart P, De Cort P, et al. Ambulatory blood pressure in normotensive and hypertensive 
subjects: results from an international database. J Hypertens Suppl 1994;12:1-12S.

13 Kikuya M, Hansen TW, Thijs L, Bjorklund-Bodegard K, Kuznetsova T, Ohkubo T, et al. Diagnostic thresholds for ambulatory blood pressure monitoring based on 10-year cardiovascular risk. Circulation 2007;115:2145-52.

14 Fagard RH, Celis H, Thijs L, Staessen JA, Clement DL, De Buyzere ML, et al. Daytime and nighttime blood pressure as predictors of death and cause-specific cardiovascular events in hypertension. Hypertension 2008;51:55-61.

15 Mancia G, Sega R, Bravi C, De Vito G, Valagussa F, Cesana G, et al. Ambulatory blood pressure normality: results from the PAMELA study. J Hypertens 1995;13:1377-90.

16 Rasmussen SL, Torp-Pedersen C, Borch-Johnsen K, Ibsen H. Normal values for ambulatory blood pressure and differences between casual blood pressure and ambulatory blood pressure: results from a Danish population survey. J Hypertens 1998;16:1415-24.

17 Bjorklund K, Lind L, Lithell H. Twenty-four hour ambulatory blood pressure in a population of elderly men. J Intern Med 2000;248:501-10.

18 Schettini C, Bianchi M, Nieto F, Sandoya E, Senra H. Ambulatory blood pressure: normality and comparison with other measurements. Hypertension Working Group. Hypertension 1999;34:818-25.

19 O’Brien E, Waeber B, Parati G, Staessen J, Myers MG. Blood pressure measuring devices: recommendations of the European Society of Hypertension. BMJ 2001;322:531-6.

20 Appel LJ, Whelton PK, Seidler AJ, Patel AR, Klag MJ. The accuracy and precision of the Accutracker ambulatory blood pressure monitor. Am J Epidemiol 1990;132:343-54.

21 Jones SC, Bilous M, Winship S, Finn P, Goodwin J. Validation of the OSCAR 2 oscillometric 24-hour ambulatory blood pressure monitor according to the international protocol for the validation of blood pressure measuring devices. Blood Press Monit 2004;9:219-23.

22 Pickering TG, Hall JE, Appel LJ, Falkner BE, Graves J, Hill MN, et al. Recommendations for blood pressure measurement in humans and experimental animals: Part 1. Blood pressure measurement in humans: a statement for professionals from the Subcommittee of Professional and Public Education of the American Heart Association Council on High Blood Pressure Research. Hypertension 2005;45:142-61.

23 Mancia G, De Backer G, Dominiczak A, Cifkova R, Fagard R, Germano G, et al. 2007 guidelines for the management of arterial hypertension: the task force for the management of arterial hypertension of the European Society of Hypertension (ESH) and of the European Society of Cardiology (ESC). J Hypertens 2007;25:1105-87.

24 Williams B, Poulter NR, Brown MJ, Davis M, McInnes GT, Potter JF, et al. British Hypertension Society guidelines for hypertension management 2004 (BHS-IV): summary. BMJ 2004;328:634-40.

25 Padwal RS, Hemmelgarn BR, McAlister FA, McKay DW, Grover S, Wilson T, et al. The 2007 Canadian Hypertension Education Program recommendations for the management of hypertension: part 1blood pressure measurement, diagnosis and assessment of risk. Can J Cardiol 2007;23:529-38.

26 Pickering T. Recommendations for the use of home (self) and ambulatory blood pressure monitoring. American Society of Hypertension Ad Hoc Panel. Am J Hypertens 1996;9:1-11.

27 Mancia G, Parati G, Pomidossi G, Grassi G, Casadei R, Zanchetti A. Alerting reaction and rise in blood pressure during measurement by physician and nurse. Hypertension 1987;9:209-15.

28 La Batide-Alanore A, Chatellier G, Bobrie G, Fofol I, Plouin PF. Comparison of nurse- and physician-determined clinic blood pressure levels in patients referred to a hypertension clinic: implications for subsequent management. J Hypertens 2000;18:391-8.

29 Ludbrook J. Comparing methods of measurement. Clin Exp Pharmacol Physiol 1997;24:193-203.

Accepted: 18 January 2010 